\section{海技術ニュース 外}

\section{サーモメカニカルパルプ配合のオフセ ッ卜新聞用紙}

[TAPPI Dec. 1977 p. 95]

マクミランの Rothesy 新聞用紙工場は日産 $900 \mathrm{t}$ で, で普通の凸版用， shallow relief（浅底）凸版用，及 びオフセット用の新聞用紙を, 北米向け 及び輸出用に製造しており，ほぼ同型の 2 台の抄紙機（製品幅 $8.8 \mathrm{~m}$ ) を有する。 化学パルプは市販の半晒 KP を使用して いるが，1976 年以前の配合は KP が 26 〜28\%，ストーン GP が 72〜74\% であ った。

$\mathrm{GP}$ は 2 工場あり, 能力は各々 $400 \mathrm{t} / \mathrm{d}$ であり,一工場はマガジングラインダー， 他の工場はポケットグラインダーである。 1975 年に半晒 KPを TMP に置換え てコスト低減を図るため, GP の一部を TMP に変換する設備投資を行い, 能力 350 t/d の Bauer 方式の TMP プラント を設置し，1976 年に運転を開始した。

\section{TMP プラントの概要}

TMP は 2 段方式で系列は 2 つる。

各系列とも，水平型スチーミングチューブ（ $1 \mathrm{~m}$ 径 $\times 8.2 \mathrm{~m}$ 長）を持っている。チップはイースタンスプ ルースとバルサムファーを $4: 1$ の割合で混ぜたもの である。スクリーンはセントリソーターで， 1 次が 4 台， 2 次が 1 台であり，5台共孔径 $2 \mathrm{~mm}$ のバスケッ トを持っている。TMP プラントには遠心型クリーナ 一は無い。

最近の操業条件を表 1 及び表 2 に示してあるが, 各 系の生産高は約 $145 \mathrm{t} / \mathrm{d}$, 電力原単位は（ 2 段後で） $2,080 \mathrm{kWh} / \mathrm{t}$ であり, フリーネスの目標值は $110 \sim$ $130 \mathrm{cc}$ である。

- 1 運転開始以来 10 力月の品質 データの移行を 示す。これは 2 段リファイナー後で每日測定したもの を月間で平均した数值であるが，これから判断すると， フリーネスを下げて沪水抵抗が高くなり, 結合ポテン シャルが増加したことが，この期間中に認められる。

\section{抄紙テスト}

2 台の抄紙機で試抄を行った目的は，TMP の使用
Table 1 Steaming Conditions of TMP System

\begin{tabular}{|l|c|}
\hline Pressure, $\mathrm{kPa}$ & $206^{1)}$ \\
Tube temperature, ${ }^{\circ} \mathrm{C}$ & $115 \sim 125$ \\
Retention time, min & 2.0 \\
Steam consumption, $\mathrm{kg} / \mathrm{ton}$ & 400 \\
\hline
\end{tabular}

1) Gauge pressure.

Table 2 Refining Conditions of TMP System

\begin{tabular}{|c|c|c|c|}
\hline & $\begin{array}{l}\text { Primary } \\
\text { refiner }\end{array}$ & $\begin{array}{l}\text { Secondary } \\
\text { refiner }\end{array}$ & Total \\
\hline $\begin{array}{l}\text { Production rate, } \\
\qquad \text { metric tons/day }\end{array}$ & $\ldots$ & $\cdots$ & 144 \\
\hline Motor load, $\mathrm{kW}$ & 7,000 & 5,500 & 12,500 \\
\hline $\begin{array}{l}\text { Specific energy consumption, } \\
\mathrm{kW} \cdot \mathrm{hr} / \mathrm{ton}\end{array}$ & 1,167 & 917 & 2,084 \\
\hline $\mathrm{CSF}, \mathrm{m} l$ & $350 \sim 400$ & $110 \sim 130$ & $\ldots$ \\
\hline $\begin{array}{l}\text { Plug wiper water flow, } \\
\text { liter/min }\end{array}$ & 208 & 113 & $\cdots$ \\
\hline $\begin{array}{l}\text { Casing shower water flow, } \\
\text { liter/min }\end{array}$ & $\cdots$ & 57 & $\cdots$ \\
\hline $\begin{array}{l}\text { Cyclone quench water flow, } \\
\text { liter } / \mathrm{min}\end{array}$ & $\cdots$ & $\cdots$ & 95 \\
\hline
\end{tabular}

Fig. 2 TMP quality trends since startup. Legend : $\square=$ line $1 ; \bullet=$ line 2 . 


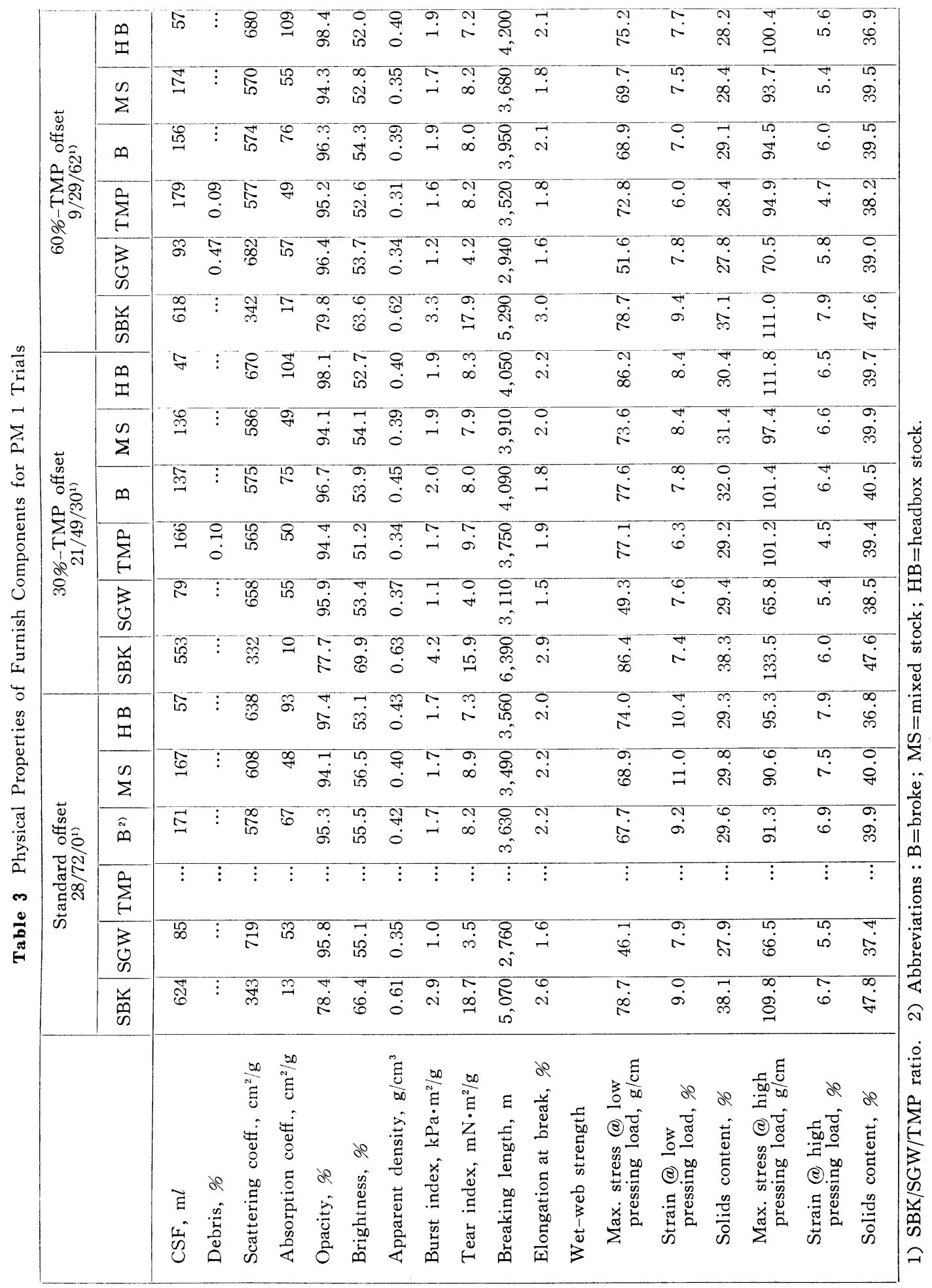


海 外技術二ュ 一 ス

Table 4 Paper Machine Data for PM 1 Trials

\begin{tabular}{|c|c|c|c|}
\hline & Standard offset & $30 \%-T M P$ offset & $60 \%$-TMP offset \\
\hline Furnish composition, SBK/SGW/TMP, \% & $28.0 / 72.0 / \cdots$ & $21.0 / 49.0 / 30.0$ & $9.1 / 29.1 / 61.8$ \\
\hline $\mathrm{CSF}, \mathrm{SBK} / \mathrm{SGW} / \mathrm{TMP} /$ Broke/Mixed Stock, $\mathrm{m} l$ & $624 / 85 / \cdots / 171 / 167$ & $553 / 79 / 166 / 137 / 136$ & $168 / 93 / 179 / 156 / 174$ \\
\hline \multicolumn{4}{|c|}{ Headbox $\quad$ } \\
\hline Total head, $\mathrm{m}$ & 8.18 & 8.76 & 8.74 \\
\hline Drag, \% & 1.5 & 1.0 & 1.2 \\
\hline Temperature, ${ }^{\circ} \mathrm{C}$ & 56 & 57 & 57 \\
\hline $\mathrm{CSF}, \mathrm{m} l$ & 57 & 47 & 57 \\
\hline Consistency, $\%$ & 0.67 & 0.70 & 0.77 \\
\hline \multicolumn{4}{|l|}{ Wire pit } \\
\hline Temperature, ${ }^{\circ} \mathrm{C}$ & 54 & 54 & 53 \\
\hline Consistency, $\%$ & 0.15 & 0.21 & 0.24 \\
\hline $\mathrm{pH}$ & 4.8 & 4.7 & 4.8 \\
\hline \multicolumn{4}{|l|}{ Wire table } \\
\hline Flat box vacuum, $1 / 2 / 3 / 4 / 5 / 6 / 7, \mathrm{~cm} \mathrm{Hg}$ & $\begin{array}{l}5.1 / 5.1 / 6.4 / 6.4 / \\
12.9 / 10.4 / 7.6\end{array}$ & $\begin{array}{l}4.1 / 5.8 / 6.1 / 6.9 / \\
12.9 / 10.2 / 7.6\end{array}$ & $\begin{array}{l}5.1 / 6.6 / 6.4 / 6.4 / \\
15.0 / 11.7 / 8.6\end{array}$ \\
\hline Dry line position & $2 \mathrm{nd}-3 \mathrm{rd}$ flatbox & 2 nd-3 rd flatbox & 2 nd-3 rd flatbox \\
\hline Couch vacuum, high/low, $\mathrm{cm} \mathrm{Hg}$ & $52.8 / 27.4$ & $52.1 / 27.9$ & $54.4 / 27.7$ \\
\hline Pick-up vacuum, cm $\mathrm{Hg}$ & 47.7 & 47.7 & 47.7 \\
\hline \multicolumn{4}{|l|}{ Press section } \\
\hline Press vacuum, $\mathrm{P} 1$, high/low, $\mathrm{cm} \mathrm{Hg}$ & $48.0 / 10.1$ & $47.7 / 12.4$ & $47.2 / 11.9$ \\
\hline Press loading, $\mathrm{P} 1 / \mathrm{P} 2 / \mathrm{P} 3 / \mathrm{W}, \mathrm{kPa}$ & $310 / 214 / 420 / 345$ & $310 / 214 / 420 / 345$ & $310 / 214 / 414 / 345$ \\
\hline \multicolumn{4}{|l|}{ Draws } \\
\hline $\mathrm{P} 2-\mathrm{P} 3, \mathrm{~m}$ & 24.4 & 21.0 & 19.2 \\
\hline P 3-D 1, m & 2.1 & 2.4 & 1.8 \\
\hline $\mathrm{D} 1-\mathrm{D} 2, \mathrm{~m}$ & 0.3 & 0 & 0 \\
\hline PU-Reel, m & 33.5 & 28.0 & 28.0 \\
\hline \multicolumn{4}{|l|}{ Calender stack } \\
\hline No. of rolls, stack $1 /$ stack 2 & $4 / 5$ & $4 / 5$ & $4 / 5$ \\
\hline No. of nips, stack $1 /$ stack 2 & $3 / 4$ & $3 / 4$ & $3 / 4$ \\
\hline No. of steam rolls, stack $1 / 2$ & $1 / 3$ & $1 / 3$ & $1 / 3$ \\
\hline Relieving pressure, stack $1 / 2$ & $152 / 165$ & $128 / 134$ & $124 / 112$ \\
\hline Paper machine speed, $\mathrm{m} / \mathrm{min}$ & 805 & 822 & 823 \\
\hline
\end{tabular}

により化学パルブがどの位減配出来るか，また抄紙機 の操業と, オフセット新聞用紙の品質にどんな影響が あるかを見極めることであった。

試抄時には，いろいろな場所でサンプリングしたパ ルプの品質試験, 抄紙機操業データの記録, 試抄品の 品質試験を行った。さらにオフセット印刷での微細繊 維取れを評価するためのサンプルを採った。

現在, TMP プラント及び抄紙機の通常の運転状態 においては，TMP 配合率は $30 \%$ が標準である。将 来の TMP プラント増設の可能性を考虑して, TMP を更に高配合した場合に，抄紙性と品質に及ぼす影響 を知るのも重要な事柄なので, \#2 m/c の修繥休転時 に\#1 m/c で TMP 60\% 配合テストを行った。
2 台の $\mathrm{m} / \mathrm{c}$ は同型であるが, TMP プラント稼動以 前はストーン GP の機種が異っていたという若干の相 異点もあるので, TMP の影響を調べるには, やはり 両方の $\mathrm{m} / \mathrm{c}$ で試抄して評価する必要があった。

\section{\#1 m/c 試抄}

TMP 配合は，0，30，60\% の 3 水準で行った。表 3 にこれら試抄品の紙質やパルプ品質などを示す。試 験は TAPPI 標準法で行ったが，湿紙強度のみは Kelk の湿紙張力測定器で測定した。

この表からみて, 標準品 $(\mathrm{TMP}=0)$ よりも, TMP 配合品の方が GP の品質が若干優れ，また KP の品質 は, TMP 30\%配合時のものが外の 2 つに比心゙, つな 
海 外 技 術二=

ぎ強度が優れている。

TMP の品質は 30\%の時も $60 \%$ の時 も略同一であり, 標準的なもので特に品 質を最高にする試みは行わなかった。

上記の単独パルプ品質の影響は, 混合 パルプ ( $\mathrm{m} / \mathrm{c}$ 白水で希釈する前の) にそ のまま反映している。

予想通り TMP の湿紙強度はストーン GP より遥かに高く, テストプレス荷重 の高い場合も低い場合でも同様である。

抄紙機関係のデータは表 4 に示す。各 試抄は 8 時間ずつ行い, 代表的なデータ を記した。SBKP 配合の変更は, TMP $30 \%$ の時は $28 \rightarrow 21 \%$ に低減し (TMP/ $\mathrm{KP}$ の置換比 4.3/1) また TMP $60 \%$ の
Table 5 Physical Properties of Newsprint for PM 1 Trials, Mill Test Laboratory Data

\begin{tabular}{|c|c|c|c|}
\hline & $\begin{array}{l}\text { Standard } \\
\text { offset }\end{array}$ & $\begin{array}{c}30 \%-T M F \\
\text { offset }\end{array}$ & $\begin{array}{c}60 \%-T M P \\
\text { offset }\end{array}$ \\
\hline Basis weight, $\mathrm{g} / \mathrm{m}^{2}$ & 47.5 & 48.8 & 48.8 \\
\hline Moisture content, $\%$ & 7.3 & 6.3 & 6.7 \\
\hline Apparent density, $\mathrm{g} / \mathrm{cm}^{3}$ & 0.61 & 0.62 & 0.60 \\
\hline Burst index, $\mathrm{kPa} \cdot \mathrm{m}^{2} / \mathrm{g}$ & 1.22 & 1.39 & 1.23 \\
\hline Tear index, $\mathrm{mN} \cdot \mathrm{m}^{2} / \mathrm{g}$ & & & \\
\hline MD & 4.42 & 3.89 & 4.53 \\
\hline C D & 5.68 & 6.35 & 6.55 \\
\hline Tensile strength, $\mathrm{MD}, \mathrm{kN} / \mathrm{m}$ & 1.43 & 1.93 & 1.83 \\
\hline Brightness, $\%$ & 58.9 & 54.5 & 53.9 \\
\hline Bendtsen porosity, $\mathrm{ml} / \mathrm{min}$ & 330 & 314 & 340 \\
\hline $\begin{array}{c}\text { Bendsen surface roughness, } \\
\text { WS, } \mathrm{ml} / \mathrm{min}\end{array}$ & 85 & 79 & 90 \\
\hline
\end{tabular}

Table 6 Physical Properties of Furnish Components for PM 2 Trials

\begin{tabular}{|c|c|c|c|c|c|c|c|c|c|c|c|c|}
\hline & \multicolumn{6}{|c|}{$\begin{array}{c}\text { Standard offset } \\
26 / 74 / 0^{1)}\end{array}$} & \multicolumn{6}{|c|}{$\begin{array}{c}30 \% \text { TMP offset } \\
17 / 52 / 31^{1)}\end{array}$} \\
\hline & SBK & SGW & TMP & B & MS & $\mathrm{HB}$ & SBK & SGW & TMP & B & MS & $\mathrm{HB}$ \\
\hline $\mathrm{CSF}, \mathrm{m} l$ & 623 & 105 & $\cdots$ & $\cdots$ & 158 & 55 & 605 & 91 & 115 & 118 & 134 & 49 \\
\hline Debris, $\%$ & $\cdots$ & $\cdots$ & $\cdots$ & $\cdots$ & $\cdots$ & $\cdots$ & $\cdots$ & 0.35 & 0.11 & $\cdots$ & $\cdots$ & \\
\hline Scattering coeff., $\mathrm{cm}^{2} / \mathrm{g}$ & 347 & 645 & $\cdots$ & $\cdots$ & 561 & 600 & 317 & 679 & 612 & 585 & 590 & 678 \\
\hline Absorption coeff,. $\mathrm{cm}^{2} / \mathrm{g}$ & 14 & 103 & $\cdots$ & $\cdots$ & 89 & 116 & 19 & 56 & 59 & 88 & 90 & 117 \\
\hline Opacity, \% & 79.6 & 98.1 & $\cdots$ & $\cdots$ & 97.0 & 97.8 & 78.8 & 96.1 & 95.8 & 97.3 & 97.2 & 98.6 \\
\hline Brightness, $\%$ & 63.1 & 49.2 & $\cdots$ & $\cdots$ & 51.2 & 48.0 & 61.3 & 53.8 & 51.4 & 52.7 & 52.8 & 51.0 \\
\hline Apparent density, $\mathrm{g} / \mathrm{cm}^{3}$ & 0.61 & 0.36 & $\cdots$ & $\cdots$ & 0.40 & 0.45 & 0.61 & 0.34 & 0.37 & 0.41 & 0.37 & 0.43 \\
\hline Burst index, $\mathrm{kPa} \cdot \mathrm{m}^{2} / \mathrm{g}$ & 3.3 & 0.9 & $\cdots$ & $\cdots$ & 1.7 & 1.8 & 3.4 & 1.0 & 1.9 & 1.9 & 1.8 & 1.9 \\
\hline Tear index, $\mathrm{mN} \cdot \mathrm{m}^{2} / \mathrm{g}$ & 19.1 & 3.7 & $\cdots$ & $\cdots$ & 8.6 & 6.7 & 18.4 & 4.3 & 7.8 & 9.1 & 8.9 & 7.0 \\
\hline Breaking length, m & 5,380 & 2,490 & $\cdots$ & $\cdots$ & 3,480 & 3,660 & 5,350 & 2,810 & 4,090 & 4,020 & 3,610 & 4,000 \\
\hline Elongation at break, \% & 2.5 & 1.4 & $\cdots$ & $\cdots$ & 2.2 & 1.9 & 2.7 & 1.6 & 2.1 & 2.1 & 2.0 & 1.9 \\
\hline Wet-web strength & & & & & & & & & & & & \\
\hline $\begin{array}{l}\text { Max. stress@ } \\
\text { low pressing load, } \\
\mathrm{g} / \mathrm{cm}\end{array}$ & 83.5 & 42.5 & $\cdots$ & $\cdots$ & 65.7 & 75.6 & 77.2 & 41.7 & 70.1 & 78.7 & 70.5 & 78.9 \\
\hline $\begin{array}{l}\text { Strain@ low } \\
\text { pressing load, \% }\end{array}$ & 8.0 & 6.9 & .. & $\cdots$ & 8.4 & 9.7 & 9.8 & 5.7 & 6.6 & 8.8 & 9.2 & 8.3 \\
\hline Solids content, $\%$ & 39.3 & 30.5 & $\cdots$ & $\cdots$ & 31.6 & 31.3 & 37.3 & 27.5 & 26.3 & 29.3 & 28.2 & 28.1 \\
\hline $\begin{array}{l}\text { Max, stress@, } \\
\text { high pressing load, } \\
\text { g/cm }\end{array}$ & 120.9 & 62.2 & $\cdots$ & $\cdots$ & 89.0 & 102.8 & 109.1 & 57.9 & 97.6 & 105.5 & 96.5 & 100.0 \\
\hline $\begin{array}{l}\text { Strain @ high } \\
\text { pressing load, \% }\end{array}$ & 5.8 & 5.2 & 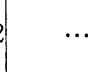 & $\cdots$ & 6.8 & 7.4 & 5.5 & 4.8 & 5.1 & 6.0 & 6.3 & 5.7 \\
\hline Solids content, $\%$ & 48.6 & 40.4 & $\cdots$ & $\cdots$ & 41.0 & 40.3 & 44.9 & 36.5 & 36.4 & 39.1 & 38.1 & 36.7 \\
\hline
\end{tabular}

1) $\mathrm{SBK} / \mathrm{SGW} / \mathrm{TMP}$ ratio. 
海 外 技 術 =

Table 7 Paper Machine Data for PM 2 Trials

\begin{tabular}{|c|c|c|}
\hline & Standard offset & $30 \%-T M P$ offset \\
\hline Furnish composition, SBK/SGW/TMP, \% & $26.0 / 74.0 / \cdots$ & $17.2 / 51.5 / 31 / 3$ \\
\hline $\mathrm{CSF}, \mathrm{SBK} / \mathrm{SGW} / \mathrm{TMP} /$ broke/mixed stack, $\mathrm{m} l$ & $623 / 105 / \cdots / \cdots / 158$ & $604 / 91 / 115 / 118 / 134$ \\
\hline \multicolumn{3}{|l|}{ Headbox } \\
\hline Total head, m & 8.51 & 8.48 \\
\hline Drag, $\%$ & 1.0 & 2.0 \\
\hline Temperature, ${ }^{\circ} \mathrm{C}$ & 51 & 56 \\
\hline $\mathrm{CSF}, \mathrm{m} l$ & 55 & 49 \\
\hline Consistency, $\%$ & 0.73 & 0.80 \\
\hline \multicolumn{3}{|l|}{ Wire pit } \\
\hline Temperature, ${ }^{\circ} \mathrm{C}$ & 51 & 56 \\
\hline Consistency, $\%$ & 0.25 & 0.204 \\
\hline $\mathrm{pH}$ & 4.6 & 4.6 \\
\hline \multicolumn{3}{|l|}{ Wire table } \\
\hline $\begin{array}{l}\text { Flat box vacuum, } \\
\qquad 1 / 2 / 3 / 4 / 5 / 6 / 7, \mathrm{~cm} \mathrm{Hg}\end{array}$ & $\begin{array}{c}2.5 / 5.1 / 7.6 / 7.6 / \\
17.5 / 14.7 / 10.9\end{array}$ & $\begin{array}{l}2.5 / 5.1 / 7.6 / 7.6 / \\
19.8 / 15.7 / 12.7\end{array}$ \\
\hline Dry line position & 2 nd-3 rd flatbox & $3 \mathrm{rd}-4$ th flatbox \\
\hline Couch vacuum, high/low, $\mathrm{cm} \mathrm{Hg}$ & $52.8 / 37.8$ & $58.4 / 40.6$ \\
\hline Pich-up vacuum, $\mathrm{cm} \mathrm{Hg}$ & 48.3 & 49.5 \\
\hline \multicolumn{3}{|l|}{ Press section } \\
\hline Press vacuum, $\mathrm{P} 1$, high/low, $\mathrm{cm} \mathrm{Hg}$ & $46.2 / 13.2$ & $48.8 / 15.7$ \\
\hline Press loading, P 1/P 2/P 3/W, kPa & $310 / 221 / 393 / 331$ & $310 / 221 / 407 / 345$ \\
\hline \multicolumn{3}{|l|}{ Draws } \\
\hline $\mathrm{P} 2-\mathrm{P} 3, \mathrm{~m}$ & 20.1 & 24.1 \\
\hline P3-D 1, m & 10.4 & 7.3 \\
\hline $\mathrm{D} 1-\mathrm{D} 2, \mathrm{~m}$ & 0.3 & 0.6 \\
\hline PU-Reel, m & 38.4 & 35.0 \\
\hline \multicolumn{3}{|l|}{ Calender stack } \\
\hline No. of rolls, stack $1 /$ stack 2 & $4 / 5$ & $4 / 5$ \\
\hline No. of nips, stack $1 /$ stack 2 & $3 / 4$ & $3 / 4$ \\
\hline No. of steam rolls, stack $1 / 2$ & $2 / 3$ & $2 / 3$ \\
\hline Relieving pressure, stack $1 / 2$ & $176 / 179$ & $145 / 152$ \\
\hline Paper machine speed, $\mathrm{m} / \mathrm{min}$ & 821 & 828 \\
\hline
\end{tabular}

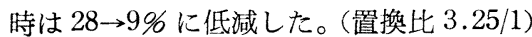

TMP を $30 \%$ 配合するとマシンのドローは著しく 減少したが，更に $60 \%$ まで増設しても更に大きく減 少することはなかった。

2 基のカレンダーともに TMP を増配した場合は, 厚さを規定值に入れるため, ニップレリーフの生力を 下げて荷重を増加させる必要があった。

試抄紙の品質を表 $\mathbf{5}$ に示す。この值は抄紙機の幅方 向に 5 力所等間隔に試料をとった平均值である。

TMP 配合 30\%のものは水分が低かったが，引張 と破裂は標準紙 $(\mathrm{TMP}=0)$ に比較して高く, TMP の結合力の強さが反映されている。
TMP 60\%配合のものは，強度の向上は見られず， 標準紙なみであった。

$\mathrm{KP}$ 减配，機械パルプ増配により，收収係数は大き くなり，白色度は低下した。

抄紙機の両端部及び中央部からオフセット卫刷機で, 試験するための巻取をとった。

\section{\#2 m/c 試抄}

\# $2 \mathrm{~m} / \mathrm{c}$ の操業条件が\# $1 \mathrm{~m} / \mathrm{c}$ と大きく買なる点の 1 つは両方の $\mathrm{m} / \mathrm{c}$ からの白水が循環する際に, \#2 m/c の方が \# $1 \mathrm{~m} / \mathrm{c}$ より回收量が多いことである。\# $2 \mathrm{~m} / \mathrm{c}$ の方が白水中の組かな繊維を多量に含み，白色度は低 
海 外 技術二ニ 一 ス

くなるが，诸強度については $\# 2 \mathrm{~m} / \mathrm{c}$ の 方が有利となる面もあった。

TMP 配合紙武抄に先立って,ブラン クとして標準紙（TMP=0）を抄造し， 抄紙機のデータと製品の品質試験を行っ た。

TMP プラントでは, パルプ品質を最 適な状態にした後に, TMP 30\%配合の 陚抄を開始した。

配合した各パルプの試験值を表 6 亿示 す。

この表から，KP は，標準紙の時も， TMP 配合の時も略同様な品質であるが, ストーン GP は, TMP 配合の場合の方 が, 標準紙の場合に比較して良好な品質 であった。

$\# 2 \mathrm{~m} / \mathrm{c}$ 武抄時は, TMP のフリーネス を\#1 m/c 試抄時より低くしたので，パ ルプ強度（引張，破裂）も\# $1 \mathrm{~m} / \mathrm{c}$ の時 上り大となっている(表 3 と表 $\mathbf{6}$ の比較)。

また $\# 2 \mathrm{~m} / \mathrm{c}$ 試抄時には，TMP $30 \%$ 配合の場合は KP を $26 \rightarrow 17 \%$ にまで域 配しているが，湿紙強度及び乾紙強度と もに，混合パルプの試験值を比べてみる と，TMP 30\%配合の方が標準紙より優 れている。
Table 8 Physical Properties of Newsprint for PM 2 Trial, Test Data on Conditioned Samples

\begin{tabular}{|l|r|r|}
\hline & $\begin{array}{c}\text { Standard } \\
\text { offset }\end{array}$ & $\begin{array}{c}30 \% \text {-TMP } \\
\text { offset }\end{array}$ \\
\hline Basis weight, g/m $\mathrm{m}^{2}$ & 49.9 & 49.3 \\
Density, g/cm ${ }^{3}$ & 0.58 & 0.59 \\
Scattering coeff., $\mathrm{cm}^{2} / \mathrm{g}$ & 579 & 598 \\
Absorption coef., $\mathrm{cm}^{2} / \mathrm{g}$ & 93 & 91 \\
Opacity, \% & 97.0 & 97.0 \\
Brightness, \% & & \\
T S & 51.0 & 53.0 \\
W S & 52.6 & 54.4 \\
Burst index, $\mathrm{kPa} \cdot \mathrm{m}^{2} / \mathrm{g}$ & 1.09 & 1.05 \\
Tea· index, $\mathrm{mN} \cdot \mathrm{m}^{2} / \mathrm{g}$ & & \\
MD & 5.2 & 4.8 \\
C D & 6.2 & 5.9 \\
Breaking length, $\mathrm{m}$ & & \\
MD & 3,760 & 4,160 \\
C D & 1,880 & 1,890 \\
Elongation, \% & & \\
MD & 0.9 & 0.9 \\
C D & 1.7 & 1.8 \\
Sheffield porosity, $\mathrm{m} l / \mathrm{min}$ & 119 & 90 \\
Sheffield surface roughness, $\mathrm{m} l / \mathrm{min}$ & & \\
T S & 144 & 128 \\
W S & 146 & 133 \\
\hline
\end{tabular}

Table 9 Linting Propensity Data for Offset Newsprint Trial Rolls

\begin{tabular}{|c|c|c|c|c|c|c|c|c|c|c|c|c|c|c|}
\hline \multirow[t]{2}{*}{$\begin{array}{l}\text { Paper machine } \\
\text { roll used }\end{array}$} & \multirow[t]{2}{*}{$\begin{array}{c}\text { Furnish } \\
\text { SBK/SGW/TMP }\end{array}$} & \multicolumn{3}{|c|}{$\begin{array}{l}\text { Offset blanket } \\
\text { lint, mg }\end{array}$} & \multicolumn{3}{|c|}{$\begin{array}{l}\text { Ink train } \\
\text { lint, mg }\end{array}$} & \multicolumn{3}{|c|}{$\begin{array}{l}\text { Total lint, } \\
\text { mg }\end{array}$} & \multicolumn{2}{|c|}{$\begin{array}{l}\text { Coarse } \\
\text { Lint, } \\
\text { mg }\end{array}$} & \multicolumn{2}{|c|}{$\begin{array}{l}\text { Coarse } \\
\text { Lint, } \\
\text { \% of } \\
\text { total }\end{array}$} \\
\hline & & T S V & WS & Total & T S & W S & Total & T S & W S & Total & T S & WS & T S & W S \\
\hline $\mathrm{PM} 1^{1)}$ & $28 / 72 / 0$ & 138 & 89 & 227 & $\mid 118$ & 126 & 244 & 256 & 215 & 471 & 34 & 41 & 14 & 21 \\
\hline $\mathrm{PM} 1^{1)}$ & $21 / 49 / 30$ & 120 & 58 & 178 & 126 & 105 & 231 & 246 & 163 & 409 & 61 & 71 & 27 & 44 \\
\hline PM $1^{1)}$ & $9 / 29 ; 62$ & 130 & 74 & 204 & 144 & 117 & 261 & 274 & 191 & 465 & 66 & 96 & 24 & 48 \\
\hline $\mathrm{PM} 2^{2)}$ & $26 / 74 / 0$ & 139 & 80 & 219 & 106 & 99 & 205 & 245 & 179 & 424 & 67 & 53 & 27 & 30 \\
\hline PM 2 & & & & & & & & & & & & & & \\
\hline 1 edge roll & $17 / 52 / 31$ & 142 & 85 & 227 & 44 & 61 & 105 & 186 & 146 & 332 & 22 & 40 & 12 & 27 \\
\hline 1 center roll & $17 / 52 / 31$ & 152 & 74 & 226 & 38 & 63 & 101 & 190 & 137 & 327 & 27 & 35 & 14 & 25 \\
\hline 1 edge roll & $17 / 52 / 31$ & 135 & 107 & 242 & 32 & 57 & 89 & 167 & 164 & 331 & 19 & 34 & 11 & 21 \\
\hline Average value & $17 / 52 / 31$ & 143 & 89 & 232 & 38 & 60 & 98 & 181 & 149 & 330 & 23 & 36 & 12 & 24 \\
\hline
\end{tabular}

1) Average values for two center and two edge rolls. 2) Average of two center rolls. 